\title{
FUNDACIÓN LUDWIG DE CUBA: PAUTAS DE DISEÑO PARA SU SISTEMA DE INFORMACIÓN DOCUMENTAL
}

\section{Yanai Valdés López}

\section{Resumen:}

Se abordan aspectos relacionados con Diseño del Sistema de Información Documental de la Fundación Ludwig de Cuba. Son expuestos los resultados de la combinación de los métodos y técnicas empleados en el diseño, para conocer la situación informacional de la organización y las más puntuales necesidades de información de sus usuarios. Se analizan las características y componentes propuestos en el diseño del Sistema de Información Documental, indicándose los procesos informacionales a desarrollar con el apoyo de las NTIC tomándose en cuenta aspectos detectados en el diagnóstico.

\section{Palabras clave:}

Diseño; Sistema de información documental; Fundación Ludwig de Cuba

\section{CUBA LUDWIG FOUNDATION: DESIGN GUIDELINES FOR DOCUMENTAL INFORMATION SYSTEM}

\begin{abstract}
:
It addresses issues related to Documental Information System Design of the Cuba Ludwig Foundation. Presents the results of the combination of methods and techniques used in the design in order to know the informational status of the organization and the specific information needs of its users. It discusses the features and components proposed for the design of Documental Information System, indicating informational processes to develop, with the support of ICT, taking into account issues identified in the diagnosis.
\end{abstract}

\section{Keywords:}

Design; Documental Information System; Cuba Ludwig Foundation 


\section{Introducción}

Es ya cotidiano por estos tiempos conocer de instituciones tales como: museos, galerías, asociaciones, fundaciones, escuelas de arte, entre otras; en las que la base para su desempeño es la información referente a las artes. Resulta para ellas ineludible contar con un sistema de información documental, pues la información sobre artes mantiene su valor de uso con el paso del tiempo, conserva vivo el legado cultural de un pueblo y oferta la posibilidad de difundir el registro de hechos culturales a través de programas de mano de concierto, registros sonoros, catálogos de exposiciones, videos de arte, entre otros que pueden ser documentos únicos e irrepetibles. La documentación atesorada por instituciones de este tipo muchas veces es resultado del registro de hechos generados o facilitados por ellas y constituyen el único registro de este hecho cultural. Lo antes expuesto justifica la propuesta de Diseño de un Sistema de Información documental para la Fundación Ludwig de Cuba (FLC). La importancia de este diseño se sustenta en la necesidad de contar con un sistema de información que:

$\checkmark$ contenga y ofrezca datos e información de sus usuarios, el ambiente y sus competencias

$\checkmark$ permita a investigadores, artistas, profesores y especialistas vinculados a la FLC, conformar o actualizar sus proyectos artísticos, investigativos y culturales nacionales y/o internacionales.

Los Sistemas de Información Documental constituyen un importante recurso dentro de las instituciones en virtud de garantizar, no sólo la organización de la documentación generada por las funciones que a las mismas le están conferidas, sino que permite captar información del ambiente externo con la finalidad de convertir entradas que tras ser procesadas pasan a ser las salidas de la unidad de información a través de diversos productos y servicios.

Los Sistemas de Información Documental se pueden tratar desde:

La Archivística, la Bibliotecología, la Documentación, la Museología y la Ciencia de la Información. En todos los casos se trata de áreas de conocimiento que adquieren, tratan, conservan y diseminan información registrada con formato impreso o digital en fuentes

(C) Revista Digital de Biblioteconomia e Ciência da Informação,Campinas, , v.7, n. 1, p. 206-223, jul./dez. 2009- ISSN: 1678-765X. 
documentales (bibliográficas, de archivo y con valor museable). Es por ello que suelen apoyarse en Bibliotecas, Centros de Información y Documentación, Archivos de gestión y Museos, para acceder a fuentes de información, documentos administrativos y objetos museables. A través de estos se puede disponer de información oportuna para la tomar decisiones. Se puede hacer alusión a ejemplos de Fundaciones que cuentan con Sistemas de Información Documental, entre ellos: Fundación Biblioteca Virtual Miguel de Cervantes, Fundación Pablo Iglesias, Fundación Lázaro Galdiano, Fundación Juan March, Fundación Hernando de Larramendi.

Estas organizaciones necesitan saber como acceder al volumen informacional que manipulan para cumplir sus funciones y difundir sus programas y proyectos. Al igual que otras entidades también manipulan documentación con fines administrativos, legales y financieros en pos de realizar su rutina de trabajo, además de utilizar fuentes de información para la investigación tales como libros, artículos, informes, resúmenes, bases de datos, información de programas y proyectos, etc.

Es justamente el caso de la ONG ${ }^{1}$ “Fundación Ludwig de Cuba” institución inaugurada el 23 de enero de 1995 como entidad de carácter autónomo, no gubernamental, pública y sin ánimos de lucro. Tiene como objeto social: "brindar apoyo institucional a los procesos creativos y de investigación que llevan a cabo artistas, especialistas, profesores e investigadores vinculados esencialmente a las artes visuales, las artes escénicas y de la representación en general, así como brindar a la experimentación y a la investigación artística apoyo intelectual que asegure su validación e inserción en los procesos de continuidad de la cultura” (FUNDACIÓN LUDWIG DE CUBA, 1995).

La misma tiene entre sus fines:

$\checkmark \quad$ crear un banco de información empleando soportes y tecnología de avanzada. El mismo deberá registrar resultados de investigaciones, fuentes especializadas, información audiovisual, etc. que sirvan como material de consulta a los artistas,

\footnotetext{
${ }^{1}$ Las fundaciones son entidades públicas o privadas creadas legal y administrativamente para canalizar, recibir o transferir recursos de determinados campos de la actividad humana, a partir de ciertos criterios, prioridades y orientaciones establecidas por cada una de ellas. Su propósito principal es otorgar recursos a otras organizaciones, instituciones o individuos para fines científicos, educativos, culturales, religiosos, $u$ otros.
}

(C) Revista Digital de Biblioteconomia e Ciência da Informação,Campinas, , v.7, n. 1, p. 206-223, jul./dez. 2009- ISSN: 1678-765X. 
$\checkmark$ sistematizar, reproducir y dar a conocer la información concerniente a la producción de los artistas, especialistas, profesores e investigadores.

El objetivo de la presente investigación es:

$\checkmark$ Explicar las características y componentes fundamentales que debe tener el Sistema de Información Documental de la Fundación Ludwig de Cuba, para facilitar el acceso a la información que respalda proyectos artísticos, investigativos y culturales.

Combinado para el diseño métodos y técnicas tales como:

$\checkmark$ Encuesta en su modalidad oral (entrevista): para conocer datos puntuales sobre la situación de las colecciones de la institución.

$\checkmark$ Encuesta en su modalidad escrita (cuestionario): para realizar un inventario de necesidades de información. Se encuestaron 104 personas, tomándose una muestra intencional en la que se incluyeron trabajadores de la institución y personas que están vinculados al trabajo de la fundación, a través de la inserción en programas y proyectos desde el 2002 hasta mayo del 2007. Los cuestionarios fueron aplicados vía e-mail y de forma presencial.

$\checkmark$ Consulta a expertos: dirigida a determinar materias a incluir en el inventario de necesidades.

La combinación de los diferentes métodos y técnicas han sido utilizadas para analizar los resultados en torno a la propuesta de diseño de sistema de información documental. 


\section{Del análisis realizado a las entrevistas se determinó que:}

La colección esta compuesta aproximadamente por 6533 documentos entre los que se encuentran: libros, revistas, catálogos de exposiciones, fotografías, diapositivas, videos, cassettes de audio y documentos en soporte digital que documentan: exposiciones, eventos, obras de arte, textos sobre exposiciones y artistas, diseños de catálogos de exposiciones, etc.

La vía fundamental de adquisición son donaciones realizadas por: Ludwig Forum für Internationale Kunst; Peter und Irene Ludwig Stiftung, American Friends of the Ludwig Foundation of Cuba, el Museo Reina Sofía de España, el Ministerio de Cultura de dicho país, entre otras. Otras entradas se realizan mediante compras y también existe la colaboración de entidades francesas relacionadas principalmente con las artes plásticas. El cubrimiento temático de los documentos incluye: arquitectura, conservación y restauración, cerámica, danza, diseño, escultura, fotografía, grabado, instalación, pintura, video arte; etc. El idioma que predomina entre ellos es el inglés, seguido del español, alemán y francés respectivamente. No se cuenta con normativas para el tratamiento de la documentación, lo que dificulta la recuperación de información a consultar. Las condiciones de almacenamiento de los documentos no son satisfactorias y no se atienden los aspectos de conservación de la colección. Las colecciones de libros, catálogos de arte cubano y revistas se almacenan en el garaje de la entidad. Los catálogos extranjeros, cassettes de audio y video, fotos y diapositivas son almacenados en armarios adaptados para este fin, en los que se puede apreciar el hacinamiento de la colección. Se añade a los problemas espaciales para el almacenamiento, la dificultad para prestar el servicio de consulta de los documentos.

La FLC como institución cultural realiza en su sede numerosas actividades: recepciones, cócteles, muestras de videos y cortos, reuniones de diversa índole, conferencias, talleres y exposiciones en áreas donde es consultada la documentación. Esto trae consigo, que para consultar la documentación se deba concertar previamente una cita.

Las preguntas formuladas en el cuestionario del Inventario de Necesidades de Información estaban encaminadas fundamentalmente a conocer:

(C) Revista Digital de Biblioteconomia e Ciência da Informação,Campinas, , v.7, n. 1, p. 206-223, jul./dez. 2009- ISSN: 1678-765X. 
Institución a la que se encuentran vinculados laboralmente los usuarios.

$\checkmark$ Ocupación que desempeña.

Vías de comunicación (Email, Teléfono).

Idioma en que puede consultar información.

$\checkmark$ Dominio de las NTIC, previendo el empleo de estas como útil herramienta del sistema.

Los recursos electrónicos que utilizan con más frecuencia.

Las áreas temáticas de su interés, así como autores y títulos de revistas que requieren, con el fin de priorizarlos al conformar las colecciones.

$\checkmark$ El tipo de información que demandan, así como su forma de presentación.

Los servicios de información que prefieren para recuperar y consultar información.

\section{Conclusiones Parciales del Inventario de Necesidades de Información.}

1. Los encuestados pertenecen a grupos, compañías, academias, centros de investigación adscritos al Ministerio de Cultura. Desarrollándose como Artista Plástico, Actor, Bailarín Crítico de arte, Conservador y Restaurador, Curador, Historiador del Arte, Investigador, Músico o Profesor indistintamente.

2. Se logro identificar el inglés como el idioma que más manejan los encuestados después del español como lengua materna.

3. La mayoría de los encuestados dominan las NTIC. 
4. Se logró identificar a los Portales y Sitios Web como el recurso electrónico que más utilizan para el desarrollo de sus trabajos.

5. Las áreas más abordadas fueron Galerías y Museos, así como Conferencias, Cursos y Talleres.

6. Los resultados arrojaron que la información de Tipo Teórica es la que se requiere en mayor medida, seguida de la Información Visual.

7. Los Catálogos de arte, los Libros y Fotos resultan los recursos documentales de mayor utilidad para los encuestados.

8. Se identificaron los autores nacionales y extranjeros consultados por los encuestados.

9. Los títulos de revistas que más demandan son Art News y Arte Cubano.

10. El Préstamo en Sala y la Búsqueda en Internet resultaron los Servicios de Información que utilizan los encuestados preferentemente.

A partir de los resultados obtenidos de las entrevistas y de los resultados del inventario de necesidades. Se hace necesario diseñar un sistema de información documental que sea capaz de satisfacer las necesidades de información de sus usuarios, permitiéndoles acceder a la información de su interés para la confección de sus programas y proyectos, la investigación y la experimentación a través de servicios de información diseñados para ellos. A la vez que solvente los problemas relacionados con la disposición espacial y la conservación de las colecciones. Todo ello ha llevado a idear un sistema de información documental con la utilización de las NTIC, en este caso un Sistema Gestor de Contenidos (Content Management Systems) que permita crear, almacenar, tratar y presentar la información en el entorno digital.

Por las posibilidades que ofrecen los sistemas gestores de contenido, se utilizará el sistema gestor GreenStone, programa confeccionado por el proyecto de Biblioteca Digital de Nueva Zelanda con respaldo de la UNESCO, para la creación y difusión de las colecciones digitales. Tramullas (2004) apunta que es un software que puede resolver los problemas básicos de tratamiento y recuperación de información que puedan plantearse 
en una unidad de información. Los requerimientos técnicos mínimos tienen un coste perfectamente asumible y la curva básica de aprendizaje es rápida. Para el usuario de consulta el proceso de aprendizaje del comportamiento de la interfaz es inmediato (...) siempre que se utilicen sus prestaciones más allá de la mera recopilación e importación de documentos, resulta una buena herramienta de soporte a una biblioteca o archivo digital. El software brinda nuevas vías para la organización de la información y su posterior publicación en INTERNET o CD-ROM. Sus colecciones pueden contener texto, imágenes, sonido y video. Permite también personalizar la interfaz, realizar búsquedas globales y procesar diferentes formatos de documentos. Además corre sobre Linux, Unix, Windows y Macintosh, es multilingüe, integra y gestiona diversos estándares de metadatos a partir de los cuales se construyen índices.

Se utilizará otro sistema gestor de contenidos para producir noticias, un RSS (Rich Site Summary), a decir de él Catalán expresa que “es un formato de texto, estándar y público, basado en el modelo de metadatos RDF, que permite distribuir titulares de noticias y contenidos a través de Internet de forma automatizada”(FRANGANILLO E CATALAN, 2005). De esta forma se producirán noticias acerca de las actividades que acontecen en la Fundación Ludwig de Cuba.

\section{Procesos a desarrollar para el diseño del Sistema de Información Digital:}

\section{Selección de los Contenidos para la Digitalización de las Fuentes de información:}

En este proceso se ajustan los recursos documentales existentes en la organización a las necesidades de los usuarios. Además de dar la posibilidad de escoger entre toda la información existente la que se aviene a formar parte del sistema, con la colaboración de los Especialistas de Arte de la FLC a fin de que aporten criterios sobre la relevancia de la información a incluir.

Ofrece la posibilidad de escoger entre toda la información existente la que se aviene a formar parte del sistema, con la colaboración de los Especialistas de Arte de la FLC a fin de que aporten criterios sobre la relevancia de la información a incluir.

(C) Revista Digital de Biblioteconomia e Ciência da Informação,Campinas, , v.7, n. 1, p. 206-223, jul./dez. 2009- ISSN: 1678-765X. 
Las variables a tener en cuenta son:

$\checkmark$ Usuarios del Sistema: Conformado por artistas, críticos de arte, conservadores y restauradores, curadores, investigadores, y profesores, vinculados a las artes visuales y escénicas, la experimentación, la investigación artística y la representación en general.

Cobertura Temática: La selección de recursos de información deberá cubrir las manifestaciones artísticas que resultaron del inventario de necesidades, relacionadas con las Artes Visuales y Escénicas.

$\checkmark$ Idioma: Los idiomas en que ha de ser seleccionada la información en primer lugar es el Español, seguido del idioma Inglés, el Portugués y el Francés.

Tipos de Recursos: Deben ser priorizados los principales recursos planteados en el inventario de necesidades. En primer lugar los Catálogos de Arte, seguido de Libros, Fotografías, Grabaciones de Audio, Revistas y Videos.

La digitalización de las colecciones de la Fundación Ludwig de Cuba se realizará de forma total. Tendrá en cuenta las necesidades de información de los usuarios y el valor que presentan los recursos para la FLC.

Se realizará de forma escalonada comenzando por las colecciones que atesoran los recursos más demandados por los usuarios. El orden de prioridad a seguir será: Catálogos de Arte, Libros, Fotografías, Grabaciones de Audio, Revistas, Videos, Diapositivas. Se realizará un inventario de los documentos digitalizados que contendrá la información siguiente:

- \# de localización en el Fondo, tipo de recurso de Información, autor, titulo, materia, formatos.

$\checkmark$ Digitalización de Materiales Impresos (Catálogos de Arte, Libros y Revistas): (FALCON, 2004) 
Serán digitalizados con el software TexT Bridge, de alta precisión al escanear, permitiendo conservar colores de gráficos y fotos como mismo fueron concebidos en el original. Además trae incluido OCR (Reconocimiento Óptico de Caracteres), aplicación para convertir a código texto la imagen escaneada, haciendo posible las correcciones del texto original y aumentar su legibilidad. La resolución para páginas en Blanco y Negro será de 300 dpi y para páginas a color de 500 dpi. El formato de salida de los documentos será PDF.

\section{$\checkmark$ Digitalización de Imágenes (Fotografías, Diapositivas):}

La digitalización de imágenes se realizara a color o en blanco y negro respetando los datos de origen de la imagen. La resolución: Blanco y Negro 300dpi a Color 500 dpi. El formato de archivo: Se realizarán dos copias de la imagen una en formato de sin compresión TIFF para guardar la imagen original sin perdida de sus propiedades y otra en formato de compresión GIF para reducir el tamaño de la imagen. Es esta la imagen que se pondrá a disposición de los usuarios con fines de difusión. Es importante encontrar un balance entre el número de bits, la resolución y el tipo de compresión para obtener una imagen aceptable para fines sólo de difusión. La utilización de un método lossless para que la representación sea exactamente igual a la original es la solución ideal.

\section{$\checkmark$ Digitalización de Grabaciones de Audio:}

Para este proceso se recomienda la contratación o convenio con la Emisora "Radio Arte", emisora que realiza el proceso de forma seria para la digitalización de sus novelas y programas solo para el caso de las grabaciones de sonido que se encuentren en Cassett.

\section{$\checkmark$ Digitalización de Videos:}

Para la digitalización se utilizará un Combo VHS-CD/DVD. Serán pasados a DVD toda la colección de videos, pero solo aquellas que se avengan a las necesidades de los usuarios se guardarán en el servidor, por ser un recurso que requiere una elevada capacidad de almacenamiento. El $\operatorname{Codec}^{2} 6$ a utilizar será el AVI pues es un formato que puede ser reproducido por cualquier computadora, además es utilizado en la institución para la edición de videos. El formato de los videos que pasarán a DVD será MPEG II,

$2 \quad$ Software utilizado primordialmente para comprimir video de forma que pueda ser adecuado para un uso especifico.

(C) Revista Digital de Biblioteconomia e Ciência da Informação,Campinas, , v.7, n. 1, p. 206-223, jul./dez. 2009- ISSN: 1678-765X. 
pues es un compresor que no degrada notoriamente la imagen y es el estándar de video del tipo DVD.

La preservación de los recursos para mantener la correcta visualización, recuperación y utilización de las colecciones se realizará teniendo en cuenta:

$\checkmark$ La degradación del soporte: Los recursos de cada una de las colecciones digitalizadas contarán con una copia maestra la cual poseerá la mayor similitud con el original y otra para la utilización que será creada a partir de maestra.

$\checkmark$ Obsolescencia de hardware: Se debe prever la sustitución de los soportes tecnológicos, velando por la posible incapacidad del hardware y los sistemas de lectura.

$\checkmark$ Obsolescencia de los formatos: Se deberá velar por la constante evolución de los formatos de almacenamiento en post de migrar la información a los nuevos formatos mismos.

$\checkmark$ Seguridad: Se debe trazar una estrategia para que no ocurran alteraciones en las colecciones.

2. Definición de los Servicios: Los servicios del sistema de información documental se prestarán a través de una biblioteca Digital. La que tendrá como propósito:

Proporcionar a artistas, críticos, curadores, investigadores y profesores vinculados a las artes escénicas y visuales de información que contribuya al desarrollo de sus programas y proyectos, además de constituir una fuente para elevar su nivel cultural.

Secciones de la Biblioteca Digital:

$\checkmark \quad$ ¿Quiénes somos?: Se expondrá información referente a la Fundación Ludwig de Cuba, su estructura, proyectos y demás información que pueda ser de interés a los 
usuarios.

$\checkmark$ Colecciones de Recursos de Información: Se dará acceso a las colecciones digitales de Catálogos de Arte, Libros, Fotografías, Cassetes de Audio, Revistas, Diapositivas y Videos.

$\checkmark$ Directorio de Recursos Web: Permitirá acceder a Bancos de Imágenes, Bibliotecas Digitales, Enciclopedias, Museos, Sitios temáticos, Sitios de artistas.

$\checkmark$ Servicio de Noticias: Sección que informará sobre talleres, cursos, conferencias, actividades, convocatorias y otorgamientos de becas, programas y proyectos destacados, exposiciones y demás actividades realizadas o coauspiciadas por la FLC, así como del acontecer nacional e internacional.

$\checkmark$ Servicio de Referencia: Se responderá a preguntas formuladas por los usuarios con la implementación del correo electrónico como herramienta idónea para tales fines.

$\checkmark$ Servicio de Diseminación Selectiva de la Información: Servicio personalizado a través del cual se le entregará información útil al usuario según sus necesidades de información, así como información sobre nuevos recursos incluidos en la colección.

\section{Arquitectura de la Información:}

La AI es la vía o forma en que los usuarios van a encontrar la información en la biblioteca Digital. Para lo que se determina sus esquemas, estructura, sistema de navegación, y sistema de etiquetado.

Esquema de Organización de la Información: Se empleará un sistema EOI ambiguo, ya que el mismo no requiere de definiciones exactas. La recuperación se realiza a través de la Consulta a las Colecciones.

$\checkmark$ Estructura de Organización de la Información: Se emplearán dos tipos de 
Estructura para acceder a los contenidos expuestos en la Biblioteca Digital. Los

EOI serán jerárquicos y basados en un modelo de base de datos relacional.

Sistema de Navegación: Se utiliza para la ubicación del usuario por el Sistema. Se utilizará un SN Global que de acceso a las principales secciones integradas por los servicios.

Sistema de Etiquetado: Se manejan para representar de forma general el contenido. Estas integrarán el Sistema de Navegación Global y se dispondrán de la forma siguiente:

\section{Etiquetas del Sistema de Navegación:}

- ¿Quiénes somos?, Colecciones de Recursos de Información, Directorios de Recursos Web, Servicio de Referencia, Servicio de DSI, Contáctenos. Es valido señalar que el Greenstone concibe etiquetas para cada una de las colecciones estas son: Colección de Catálogos de Arte, Colección de Casetes de Audio, Colección de Diapositivas, Colección de Fotografías, Colección de Libros, Colección de Revistas, Colección de Videos.

\section{Etiquetas del Sistema de Cabeceras o Títulos:}

Las mismas estarán en correspondencia con los bloques de información. Se utilizarán como títulos:

¿Quiénes somos?, Colecciones de Recursos de Información, Directorios de Recursos Web, Servicio de Referencia, DSI, Contáctenos.

\section{Etiquetas del Sistema de Indización:}

Se utilizará el sistema de metadatos Dublín Core (8) y contendrá los datos de contenido como título, materia descripción, fuente, idioma, cobertura. Además se reflejarán datos de 
propiedad intelectual, tales como autor, colaboradores. Y otros datos que harán referencia a la fecha de publicación del recurso, el identificador del recurso.

\section{Sistema de Búsqueda y Recuperación:}

La búsqueda y recuperación en el sistema una vez definidos los metadatos para cada uno de los recursos, se realizará a través de:

Búsqueda a través de Índices, en los cuales el usuario visualiza índices alfabéticos de entradas a la información. La búsqueda estará regulada en dependencia del tipo de colección. Pues todas presentan sus peculiaridades propias.

Búsqueda directa: a través de esta el usuario formula de forma directa la prescripción de búsqueda en un cuadro de dialogo que presenta el software destinado para este fin y a través del cual se realizarán búsquedas basadas en todas las palabras o basadas en algunas palabras. Con la búsqueda basada en todas las palabras el sistema buscará en todos los documentos, títulos, capítulos, contenido del recurso que contengan todas las palabras que se han especificado. La búsqueda basada en algunas palabras indican los términos que se corresponden en algún grado con el especificado. Representando los documentos según el orden de pertinencia de la consulta.

Búsqueda avanzada: con la que se podrá establecer las preferencias de la consulta. El software permite una vez especificado el término de búsqueda preferir que las mayúsculas y minúsculas que aparezcan en la consulta este en correspondencia con las del documento. Permite también realizar truncamiento de términos al no hacer caso a los fines de palabras.

El vocabulario utilizado para la descripción de contenido será el Tesauro de la UNESCO publicado en 1995 por la Organización de Naciones Unidas para la Educación, la ciencia y la Cultura.

\section{Diseño de la interfaz gráfica:}

Fuente tipográfica: Se selecciona para como fuente tipografía Georgia del tipo

(C) Revista Digital de Biblioteconomia e Ciência da Informação,Campinas, , v.7, n. 1, p. 206-223, jul./dez. 2009- ISSN: 1678-765X. 
Sans Serif por ser una tipografía muy legible en pantalla, con un tamaño de 10 a 14 puntos. Se usará un fondo blanco y gris que se avenga con los colores negro y azul de la tipografía.

Zonas de los elementos de navegación: Se usará el logo de la FLC en parte superior izquierda de la página unido a un banner. Un menú vertical dará acceso a las secciones. En la región izquierda se situarán un espacio a anuncios publicitarios, que definirá la Junta Directiva relacionados con el mundo del arte. El prototipo preliminar se muestra en el Anexo \#1.

\section{Consideraciones Finales:}

El resultado de los estudios realizados muestran la necesidad de establecer un sistema para facilitar información a los usuarios para conformar y actualizar sus programas y proyectos.

El Sistema de Información Documental de la Fundación Ludwig de Cuba se constituirá como un subsistema dentro de la organización.

Dadas las características y disponibilidad espacial de la FLC se decidió diseñar el sistema soportado en las NTIC, para brindar sus servicios mediante una biblioteca digital, ofreciendo al usuario una perspectiva de acceso de forma electrónica a los recursos de información.

El sistema de información documental realizará procesos que permitan digitalizar y conformar las colecciones de recursos de información digital, así como entregar a los usuarios información útil de su interés por esta vía.

$\checkmark$ La Arquitectura de la Información propuesta se basa en los resultados del estudio de necesidades, centrándose por tanto en los intereses de la audiencia, abarcando los contenidos demandados por la misma y estructurados de una forma factible de acuerdo a lo especificado en el estudio. 


\section{Referencias bibliográficas:}

CUBA. Fundación Ludwig de Cuba. Estatutos de la Fundación Ludwig de Cuba. 1995. p.1.

DEL sonido de vinilo al MP3. [en línea] disponible en: http://www.hispamp3.com/noticias/0011/001125_4.shtml. [Consultado: 23 de enero 2008].

FALCÓN, V. Propuesta metodológica par el diseño e implementación de un proyecto de diseño de textos en unidades de información de Ciudad Habana. [tesis de licenciatura]. Universidad de la Habana. Facultad Comunicación. Bibliotecología y Ciencias de la información; 2004. 31p.

FRANGANILLO, J; CATALAN, M. A. Bitácoras y sindicación de contenidos: dos herramientas para difundir información. BID textos universitaris de biblioteconomia i documentació , n.15, desembre de 2005. Disponible en:

http://www.ub.edu/bid/15frang2.htm [Consultado: 1 de febrero 2008].

MANUAL de proceso de captura de vídeo. [en línea] disponible en: http://www.unav.es. [Consultado: 23 de enero 2008].

MÉNDEZ, E. Metadatos y Recuperación de información. Estándares, problemas y aplicabilidad en bibliotecas digitales. Asturias, 1998. p.147.

TRAMULLAS J, Garrido P. Un experimento de creación de biblioteca digital con Greenstone. El Profesional de la Información, 2004; 13(2), 84-92.

UNIVERSIDAD DE CORNELL. Tutorial de Digitalización de Imágenes. [en línea] disponible en: $\quad$ http://www.library.cornell.edu/preservation/tutorialspanish/contents.html. [Consultado: 28 de enero 2008]. 


\section{Yanai Valdés López}

Licenciada en Bibliotecología y Ciencias de la Información. Adiestrada del Grupo de Automatización de la Dirección de Información Científico Técnica de la Universidad de la Habana. DICT sito en Calle San Lázaro y L. Vedado, Ciudad de la Habana, Cuba.

yvaldes@dict.uh.cu; valdeslopez84@gmail.com

Recebido em: 05/05/2008

Aceito para publicação em: jan/2009 


\section{Anexo 1: Prototipo de diseño de la interfaz gráfica.}

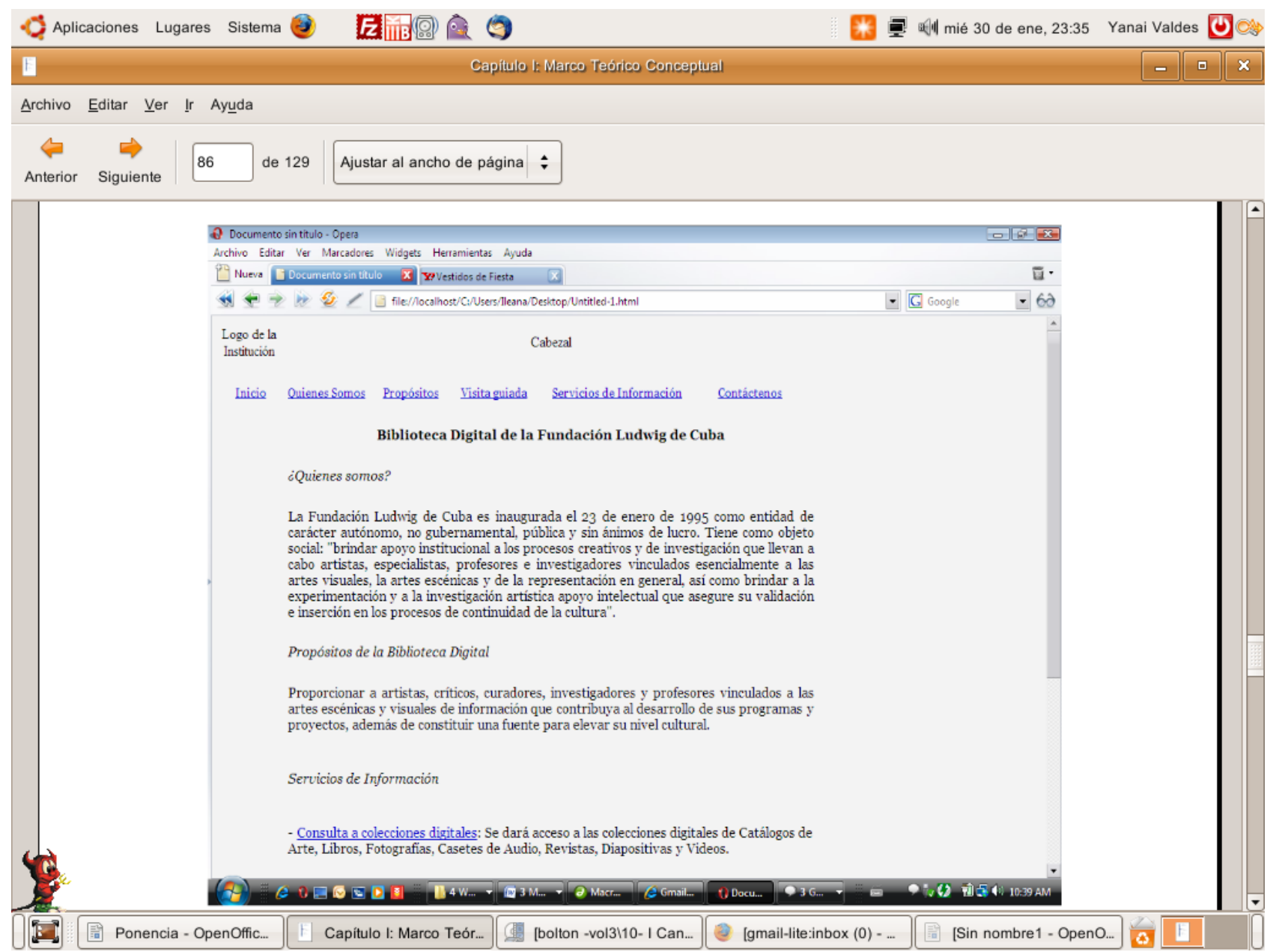

